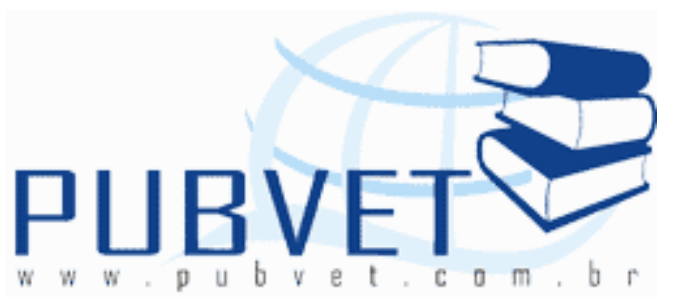

PUBVET, Publicações em Medicina Veterinária e Zootecnia.

\title{
Compactação de um Latossolo Amarelo sob pastagem submetida a diferentes métodos de introdução de leguminosas forrageiras
}

Claudio Ramalho Townsend ${ }^{1}$, Newton de Lucena Costa ${ }^{2}$, Ângelo Mansur Mendes ${ }^{3}$, Ricardo Gomes de Araujo Pereira ${ }^{1}$, Lucia Elenícia da Silva Nascimento $^{4}$, João Avelar Magalhães ${ }^{5}$

${ }^{1}$ Zootecnista, D.Sc., Pesquisador da Embrapa Rondônia. Porto Velho, Rondônia.

2 Eng. Agr., M.Sc., Pesquisador da Embrapa Roraima. Boa Vista, RR. Doutorando da UFPR.

${ }^{3}$ Eng. Agr., M.Sc., Pesquisador da Embrapa Rondônia.

${ }^{4}$ Pós-graduanda em Gestão Ambiental, Faculdade Montenegro. Parnaíba, Piauí.

${ }^{5}$ Méd. Vet., D.Sc., Pesquisador da Embrapa Meio-Norte. Parnaíba, Piauí.

\section{Resumo}

Em Porto Velho, Rondônia, foram avaliados os efeitos de diferentes métodos de introdução de leguminosas forrageiras sobre a compactação e a umidade de um Latossolo Amarelo distrófico, textura argilosa, sob pastagem de Brachiaria brizantha cv. Marandu em processo de degradação. Foi adotado o delineamento experimental de blocos ao acaso com três repetições, em arranjo fatorial $2 \times 5 \times 2 \times 10$ representados pelas leguminosas (Desmodium ovalifolium ou Pueraria phaseoloides), métodos de estabelecimento/preparo do solo (roço, aração, gradagem, aração + gradagem e plantio manual com 
matraca), adubação fosfatada ( 0 e $50 \mathrm{~kg} \mathrm{ha}^{-1}$ de $\mathrm{P}_{2} \mathrm{O}_{5}$ ) e 10 profundidades do solo (camadas de $5 \mathrm{~cm}$ no perfil de 0 a $50 \mathrm{~cm}$ ) quando se avaliou a resistência à penetração, para umidade foram 2 profundidades (camadas de $15 \mathrm{~cm}$ no perfil do solo 0 a $30 \mathrm{~cm}$ ). A resistência à penetração foi determinada com auxilio de penetrômetro de impacto, modelo IAA/Planalsucar-Stolf em cinco pontos das parcelas, e a umidade por diferença no peso inicial e final após secagem de amostras deformadas. Independentemente da intensidade de preparo do solo e da fosfatagem a introdução das leguminosas forrageiras propiciou redução na resistência à penetração do solo, com destaque ao $D$. ovalifolium, esse efeito foi mais evidente quando conciliado ao método de maior revolvimento do solo (gradagem + aração), notadamente na camada superficial (0 a $15 \mathrm{~cm}$ ).

Termo para indexação: Brachiaria brizantha, Desmodium ovalifolium, Pueraria phaseoloides

\title{
Soil compaction of a Yellow Latosol under pasture submitted to different methods of introduction of forage legumes
}

\begin{abstract}
In Porto Velho, Rondônia, was evaluated the effects of different methods of introduction of forage legumes on the soil compaction and moisture of a dystrophic Yellow Latosol, clay texture, under pasture of Brachiaria brizantha $\mathrm{cv}$. Marandu in the process of degradation. We adopted the experiment in design of randomized blocks with three replicates, in a factorial arrangement 2 $\times 5 \times 2 \times 10$ to the legumes (Desmodium ovalifolium or Pueraria phaseoloides), methods of establishment/tillage (grazed, plowing, harrowing, plowing + harrowing and manual plantation), phosphate fertilization (50 and $100 \mathrm{~kg} \mathrm{ha}^{-1}$ $\mathrm{P}_{2} \mathrm{O}_{5}$ ) and 10 depths of the soil (layer the $5 \mathrm{~cm}$ of the profile $0-50 \mathrm{~cm}$ ) when measuring the penetration resistance, for moisture were 2 depths (layer the 15 $\mathrm{cm}$ of the profile $0-30 \mathrm{~cm}$ ). The resistance to penetration was determined with the aid of an impact penetrometer, model IAA/Planalsucar-Stolf in five points
\end{abstract}


of the plots, and moisture by difference in initial and final weight after drying of deformed samples. Independently of the intensity of tillage and phosphate the introduction of legumes caused a reduction in resistance to penetration of the soil, with emphasis on $D$. ovalifolium, this effect was more evident when reconciled the method more soil tillage, especially in the surface layer ( 0 to 15 $\mathrm{cm})$.

Index terms: Brachiaria brizantha, Desmodium ovalifolium, Pueraria phaseoloides

\section{Introdução}

Os dados disponibilizados pelo INPE (2011) mostram que a área desmatada na Amazônia Legal Brasileira já ultrapassa $730.000 \mathrm{~km}^{2}$. Desse total, estima-se que cerca de $70 \%$ são usados em algum período com pastagens. Em Rondônia a área desmatada até 2009 foi estimada em 84.891 $\mathrm{km}^{2}$, correspondendo $35 \%$ do seu território, perfazendo mais de 5,5 milhões de ha de pastagens, que são a principal base alimentar de um rebanho com quase 12 milhões de bovinos (IDARON, 2010; INPE, 2011). Dessa área aproximadamente $40 \%$ se apresenta em algum estágio de degradação, em decorrência de vários fatores, com destaque ao declínio da fertilidade do solo, manejo inadequado do sistema solo-planta-animal e altas pressões bióticas exercidas por insetos e doenças, o que compromete a sustentabilidade dos sistemas pastoris (DIAS FILHO, 2005).

Diante deste cenário os métodos tradicionais de manutenção das pastagens (queima e limpeza) utilizados por grande parte dos pecuaristas, tornam-se cada vez menos eficientes, obrigando-os a abandonar a atividade; ou avançarem sobre novas áreas de floresta, resultando em uma "pecuária itinerante", com enormes custos bio-socio-econômicos, redundando na insustentabilidade do sistema de produção. Neste contexto, cada vez mais vem sendo exigido a adoção de medidas que visem à recuperação/renovação de pastos e de intensificação do uso da terra e mão-de-obra no Bioma Amazônia (REBELLO; HOMMA, 2005). 

diferentes métodos de introdução de leguminosas forrageiras. PUBVET, Londrina, V. 6, N. 13, Ed. 200, Art. 1339, 2012.

Como regra geral, essas pastagens seguem em maior ou menor grau, os padrões produtivos descritos por Serrão e Toledo (1994), quais sejam: após derrubada e queima da floresta primária, a área pode ser cultivada por um breve período com lavouras; em seguida se estabelece a pastagem, via de regra, esta apresenta bons níveis de produtividade durante os primeiros anos de utilização. Paulatinamente há decréscimo na produtividade e incremento de plantas invasoras, face a incapacidade da gramínea forrageira sustentar bons rendimentos em níveis baixos de fertilidade, sendo o fósforo $(P)$ o elemento mais limitante, muito embora, em pasto com avançado estágio de degradação, o nitrogênio ( $N$ ) e o potássio (K) também passam a ser limitantes, em decorrência dos baixos teores de matéria orgânica (MO) no solo (TOWNSEND et al., 2001) e ineficiente ciclagem desses nutrientes no sistema pastoril.

Concomitantemente há o comprometimento das propriedades físicas do solo, podendo culminar na sua compactação ${ }^{1}$, que potencializa a degeneração da pastagem, conforme constatado em trabalhos de levantamento temporal da substituição da floresta por pastagens cultivadas nos estados de Rondônia (LEÔNIDAS, 1998; NUMATA et al., 2003) e Acre (COSTA et al., 1999).

Silva Filho et al. (2010) avaliando a compactação dos solos em áreas de pastagens com mais de 20 anos de uso, sobre um Latossolo Amarelo de textura argilosa e outro de textura muito argilosa, em Porto Velho/RO, obtiveram valores relativos à resistência mecânica à penetração no solo, da

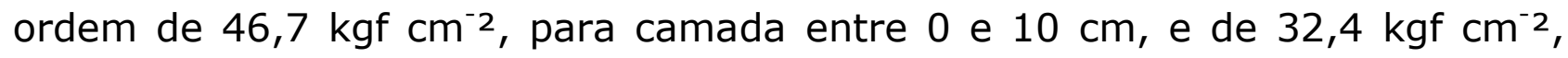
para camadas entre 11 e $20 \mathrm{~cm}$ de profundidade, evidenciando alto grau de compactação, considerando os valores preconizados pela USDA (1993) como impeditivos ao crescimento radicular de vários cultivos agrícolas.

A compactação, além de ser um impedimento mecânico ao crescimento radicular, afeta os processos de aeração, condutividade ao ar, à água e ao calor, infiltração e redistribuição da água, além dos processos químicos e

\footnotetext{
${ }^{1}$ Entende-se por compactação como sendo a compressão do solo não saturado durante a qual existe um aumento de sua densidade em consequência da redução de seu volume, resultando na expulsão de ar dos poros do solo (CAMARGO e ALLEONI, 1997).
} 
biológicos (CAMARGO; ALLEONI, 1997). Esses autores descreveram que tais condições refletem sobre as plantas cultivadas, sendo perceptível: a emergência lenta da plântula; plantas com tamanhos variados, tendo mais plantas pequenas que normais; plantas de coloração deficiente; sistema radical raso; e raízes malformadas com maior incidência de pêlos absorventes. Enquanto que no solo são evidentes: a formação de crosta superficial; fendas nas marcas das rodas de máquinas e equipamentos; zonas compactadas de subsuperfície; empoçamento de água; erosão excessiva pela água; aumento da necessidade de potência de máquinas para cultivos; e presença de restos de resíduos não decompostos meses após a incorporação.

A quantificação do grau de compactação de um solo, pode ser avaliada a partir de diversos atributos do solo, tais como: porosidade, densidade, infiltração de água, resistência ao penetrômetro. Esse último parâmetro vem sendo bastante difundido e utilizado dado sua facilidade e rapidez de determinação, no entanto a interpretação de seus resultados requer certa precaução, pois está diretamente relacionado a textura e densidade do solo, e inversamente a umidade do mesmo (MANIERI, 2005).

Esse trabalho teve por objetivo avaliar a compactação e a umidade de um Latossolo Amarelo distrófico, textura argilosa sob pastagens de Brachiaria brizantha cv. Marandu em processo de degradação, submetida a diferentes métodos de introdução de leguminosas forrageiras.

\section{Material e métodos}

As avaliações de resistência à penetração e umidade do solo foram realizadas em um experimento conduzido no Campo Experimental da Embrapa Rondônia, em Porto Velho. O clima é tropical úmido, com estação seca bem definida (junho a setembro); precipitação anual de 2.000 a 2.500 mm; temperatura média de $24,9{ }^{\circ} \mathrm{C}$ e umidade relativa do ar de $89 \%$.

A área experimental consistiu de uma pastagem de Brachiaria brizantha cv. Marandu, estabelecida há mais de dez anos, caracterizada como em degradação dado ao baixo vigor e disponibilidade da gramínea e 
predominância de plantas invasoras (30 a 50\% da cobertura do solo). Seu solo foi classificado como Latossolo Amarelo distrófico, textura argilosa, com as seguintes características químicas na profundidade de 0 a $20 \mathrm{~cm}: \mathrm{pH}=4,8 ; \mathrm{P}$ $=1,0 \mathrm{mg} \mathrm{dm}{ }^{-3} ; \mathrm{Al}=1,4 \mathrm{cmol}_{\mathrm{c}} \mathrm{dm}^{-3} ; \mathrm{Ca}+\mathrm{Mg}=2,2 \mathrm{cmol}_{\mathrm{c}} \mathrm{dm}^{-3} ; \mathrm{K}=0,04$ $\mathrm{cmol}_{\mathrm{c}} \mathrm{dm}^{-3}$ e $\mathrm{MO}=30,2 \mathrm{~g} \mathrm{~kg}^{-1}$.

O delineamento experimental foi em blocos casualizados com três repetições, em arranjo fatorial $2 \times 5 \times 2 \times 10$ representados pela introdução de leguminosas forrageiras (Desmodium ovalifolium ou Pueraria phaseoloides), métodos de estabelecimento/preparo do solo (roço, aração, gradagem, aração + gradagem e plantio manual com matraca das leguminosas), adubação fosfatada ( 0 ou $50 \mathrm{~kg} \mathrm{ha}^{-1}$ de $\mathrm{P}_{2} \mathrm{O}_{5}$ ), e profundidades do solo $(0-5,5-10,10$ $15,15-20,20-25,25-30,30-35,35-40,40-45$ e 45-50 cm). Foram mantidas e avaliadas parcelas controle que serviram como referência da condição inicial do solo. Cada parcela experimental media $15 \times 10 \mathrm{~m}$ perfazendo uma área de 150 $\mathrm{m}^{2}$.

Nos tratamentos onde se procedeu preparo de solo (aração, gradagem e aração + gradagem), as operações foram realizadas no início do período chuvoso, após o rebaixamento da vegetação (pastejo/roço mecânico da pastagem), utilizando-se grade e arado de discos, não havendo revolvimento do solo nas parcelas em que as leguminosas foram estabelecidas após o roço e com plantio manual. Em seguida, procedeu-se a distribuição a lanço de cloreto de potássio ( $60 \mathrm{~kg}$ de $\mathrm{K}_{2} \mathrm{O} \mathrm{ha}{ }^{-1}$, em todas as parcelas) e do superfosfato triplo (50 kg ha ${ }^{-1}$ de $\mathrm{P}_{2} \mathrm{O}_{5}$, apenas nas parcelas submetidas a esse fator). As leguminosas foram semeadas, conforme o método de estabelecimento, a lanço ou matraca (manual), nas densidades de 1,5 e $2,0 \mathrm{~kg} \mathrm{ha}^{-1}$ de sementes ( $\mathrm{VC}=$ $90 \%$ ), respectivamente para $D$. ovalifolium e $P$. phaseoloides, não houve ressemeadura da gramínea forrageira.

Conforme a disponibilidade de forragem, esporadicamente toda a área experimental foi submetida ao pastoreio por novilhos (as) Holandês $x$ Zebu, procurando-se manter a lotação próxima a $1 \mathrm{UA} \mathrm{ha}^{-1}$ (450 kg de PV) e a altura da pastagem próxima a $30 \mathrm{~cm}$. 
Decorridos 3,5 anos (janeiro de 1995 e junho 1998) de avaliação agronômica do acúmulo de forragem, se determinou a resistência do solo à penetração com auxilio de penetrômetro de impacto, modelo IAA/PlanalsucarStolf, descrito por Stolf et al. (1983). Para tanto se utilizou a relação entre o número de impactos despendidos e o comprimento da haste que penetra no

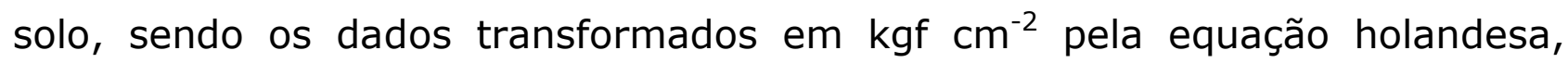
simplificada por Stolf (1991):

onde:

\begin{tabular}{|llll}
\hline$R$ & $\left(\mathrm{kgf} \mathrm{cm}^{-2}\right)=5,6+6,89$ & $\mathrm{~N}$ \\
\hline
\end{tabular}

$\mathbf{R}$ é a resistência do solo a penetração em $\mathrm{kgf} \mathrm{cm}^{-2}$;

$\mathbf{N}$ é o número de impactos por decímetro $(\mathrm{dm})$, obtido por:

$\mathrm{N}\left(\right.$ impactos $\left.\mathrm{dm}^{-1}\right)=\left[\mathrm{n}^{\circ}\right.$ de impactos $\div$ profundidade $\left.(\mathrm{cm}) \quad\right] \times 10$

As avaliações foram realizadas em cinco pontos representativos de cada parcela experimental, na profundidade de 0 a $50 \mathrm{~cm}$, em escala de 5 em $5 \mathrm{~cm}$. $\mathrm{O}$ teor de umidade do solo foi determinado com base no peso de amostras deformadas, antes e após secagem em estufa a $105^{\circ} \mathrm{C}$, conforme metodologia descrita pela Embrapa (1999). As amostras foram coletadas às profundidades de 0 a $15 \mathrm{~cm}$ e 15 a $30 \mathrm{~cm}$, e análisadas no Laboratório de Analise de Solo da Embrapa Rondônia. Os resultdos obtidos foram submetidos a análise de variância e as médias comparadas entre si pelo teste de Tukey.

\section{Resultados e discussão}

A resistência do solo à penetração foi influenciada $(P<0,01)$ pela espécie de leguminosa forrageira introduzida e métodos de estabelecimento/preparo do solo, bem como pela interação dos dois primeiros fatores com a profundidade no perfil do solo (Tabela 1). 
TOWNSEND, C.R. et al. Compactação de um Latossolo Amarelo sob pastagem submetida a diferentes métodos de introdução de leguminosas forrageiras. PUBVET, Londrina, V. 6, N. 13, Ed. 200, Art. 1339, 2012.

Tabela 1. Efeito da introdução de leguminosas forrageiras sob diferentes métodos de semeadura e preparo de solo na resistência a penetração em um Latossolo Amarelo distrófico, textura argilosa, sob pastagens de Brachiaria brizantha cv. Marandu. Porto Velho-RO.

\begin{tabular}{|c|c|c|c|c|c|c|c|c|c|c|c|}
\hline \multirow{3}{*}{ Tratamentos } & \multicolumn{10}{|c|}{ Profundidade do solo $(\mathrm{cm})$} & \multirow{2}{*}{ Média } \\
\hline & $00-05$ & $05-10$ & $10-15$ & $15-20$ & $20-25$ & $25-30$ & $30-35$ & $35-40$ & $40-45$ & $45-50$ & \\
\hline & \multicolumn{11}{|c|}{$\mathrm{kgf} \mathrm{cm}^{-2}$} \\
\hline $\begin{array}{l}\text { Leguminosa } \\
\text { P. phaseoloides } \\
\text { D. ovalifolium }\end{array}$ & $\begin{array}{c}\mathrm{A} 15,5^{\mathrm{b}} \\
{ }^{\mathrm{B}} 12,2^{\text {de }} \\
\end{array}$ & $\begin{array}{l}{ }^{\mathrm{A}} 18,7^{\mathrm{a}} \\
{ }^{\mathrm{B}} 16,0^{\mathrm{b}} \\
\end{array}$ & $\begin{array}{l}\mathrm{A} 18,8^{\mathrm{a}} \\
{ }^{\mathrm{B}} 17,7^{\mathrm{a}} \\
\end{array}$ & $\begin{array}{l}{ }^{\mathrm{A}} 16,4^{\mathrm{b}} \\
{ }^{\mathrm{A}} 16,0^{\mathrm{b}} \\
\end{array}$ & $\begin{array}{l}{ }^{\mathrm{A}} 14,1^{\mathrm{C}} \\
{ }^{\mathrm{A}} 14,4^{\mathrm{C}}\end{array}$ & $\begin{array}{l}\mathrm{A} 12,5^{\mathrm{d}} \\
{ }^{\mathrm{A}} 13,0^{\mathrm{d}} \\
\end{array}$ & $\begin{array}{l}{ }^{\mathrm{A}} 12,0^{\text {de }} \\
{ }^{\mathrm{A}} 12,2^{\text {de }}\end{array}$ & $\begin{array}{l}\mathrm{A} 11,4^{\text {ef }} \\
{ }^{\mathrm{A}} 11,5^{\text {ef }} \\
\end{array}$ & $\begin{array}{l}{ }^{A} 10,5^{f} \\
{ }^{A} 11,0^{f}\end{array}$ & $\begin{array}{l}{ }^{\mathrm{A}} 10,4^{\mathrm{f}} \\
{ }^{\mathrm{A}} 10,9^{\mathrm{f}} \\
\end{array}$ & $\begin{array}{l}14,0^{\mathrm{A}} \\
13,5^{\mathrm{B}} \\
\end{array}$ \\
\hline \multicolumn{12}{|l|}{ Método } \\
\hline Roço & ${ }_{c}^{\mathrm{AB}} 14,6^{\mathrm{b}}$ & ${ }^{A B} 18,2^{a}$ & ${ }^{A B} 18,4^{a}$ & ${ }^{\mathrm{A}} 16,1^{\mathrm{b}}$ & $\mathrm{A} 13,9^{\mathrm{cd}}$ & ${ }^{\mathrm{A}} 12,5^{\mathrm{de}}$ & ${ }^{\mathrm{A}} 11,9^{\mathrm{ef}}$ & ${ }^{\mathrm{A}} 11,2^{\mathrm{ef}}$ & ${ }^{A} 10,6^{f}$ & ${ }^{A} 10,6^{f}$ & $13,8_{A B}$ \\
\hline Aração (A) & $\begin{array}{c}{ }^{A B C} 13 \\
7^{b c}\end{array}$ & ${ }^{\mathrm{BC}} 16,9^{\mathrm{a}}$ & ${ }^{A B} 18,4^{a}$ & ${ }^{\mathrm{A}} 16,9^{\mathrm{a}}$ & ${ }^{\mathrm{A}} 14,7^{\mathrm{b}}$ & ${ }^{\mathrm{A}} 12,9^{\mathrm{bcd}}$ & ${ }^{\mathrm{A}} 12,2^{\text {cde }}$ & ${ }^{\mathrm{A}} 11,5^{\mathrm{de}}$ & ${ }^{A} 10,8^{e}$ & ${ }^{A} 10,9^{e}$ & $13,8^{A B}$ \\
\hline Gradagem (G) & ${ }^{B C} 13,2^{e}$ & ${ }^{c} 16,7^{a b}$ & ${ }^{A B} 17,9^{a}$ & ${ }^{\mathrm{A}} 15,7^{\mathrm{bc}}$ & $\mathrm{A} 13,9^{\mathrm{cd}}$ & ${ }^{\mathrm{A}} 12,1^{\mathrm{ef}}$ & ${ }^{\mathrm{A}} 11,9^{\mathrm{ef}}$ & ${ }^{A} 11,3^{f}$ & ${ }^{A} 10,9^{f}$ & ${ }^{A} 10,5^{f}$ & $13,4^{\mathrm{B}}$ \\
\hline$A+G$ & ${ }^{c_{12}} 6^{d}$ & $\mathrm{c}_{15,8^{\mathrm{b}}}$ & ${ }^{\mathrm{B}} 17,6^{\mathrm{a}}$ & ${ }^{\mathrm{A}} 15,9^{\mathrm{ab}}$ & ${ }^{\mathrm{A}} 14,4^{\mathrm{bc}}$ & ${ }^{\mathrm{A}} 12,9^{\mathrm{cd}}$ & ${ }^{\mathrm{A}} 12,2^{\mathrm{de}}$ & ${ }^{\mathrm{A}} 11,9^{\text {de }}$ & ${ }^{\mathrm{A}} 10,5^{\mathrm{e}}$ & ${ }^{\mathrm{A}} 10,5^{\mathrm{e}}$ & $13,4^{\mathrm{B}}$ \\
\hline Média & $14,1 \mathrm{~d}$ & $17,8 \mathrm{~b}$ & $18,5 a$ & $16,3 c$ & $14,3 \mathrm{~d}$ & $12,8 \mathrm{e}$ & $12,1 \mathrm{ef}$ & $11,4 \mathrm{fg}$ & $10,7 \mathrm{gh}$ & $10,6 \mathrm{~h}$ & 13,9 \\
\hline Controle & 15,3 & 20,0 & 19,8 & 16,2 & 14,9 & 13,2 & 12,4 & 11,1 & 10,8 & 10,6 & 14,5 \\
\hline
\end{tabular}

A introdução de $D$. ovalifolium (Figura 1-a) conferiu menor resistência à penetração, notadamente na camada superficial do solo $(5$ a $15 \mathrm{~cm}$ ), comparativamente à de $P$. phaseoloides. As leguminosas contribuíram efetivamente no rompimento da camada de impedimento, ao se considerar as parcelas controle, onde a resistência média foi de $20 \mathrm{kgf} \mathrm{cm}^{-2}$, podendo-se inferir que atuaram como "arado biológico". Azevedo et al. (2007) também propõem essa terminologia ao se referirem a capacidade do sistema radicular do guandu (Cajanus cajan) em romper camadas adensadas do solo, pois são raízes pivotantes, profundas e adensadas.

À medida que se intensificou o preparo do solo a pressão aplicada foi decrescente, principalmente na camada de 0 a $15 \mathrm{~cm}$ (Figura 1-b), sob a qual os implementos utilizados surtiram melhor efeito em sua descompactação. Em experimento semelhante conduzido nas mesmas condições edafoclimáticas, Figueiredo et al. (2000) constataram que a introdução de $P$. phaseoloides associada à aração + gradagem do solo foi o método mais eficiente no rompimento da camada de impedimento. Leônidas (1998) observou que o solo sob floresta ofereceu menor resistência à penetração quando comparado ao solo sob pastagens, havendo incremento com o tempo de utilização dos pastos, o que também foi evidenciado por Costa et al. (1999). No mesmo 
campo experimental, Silva Filho et al. (2010) detectaram resposta semelhante, ao compararem pastos formados em diferentes classes de solos, sendo que as camadas superficiais ( 0 a $20 \mathrm{~cm}$ ) do Latossolo Amarelo ofereceram maior resistência que as do Argissolo Vermelho Amarelo, ambos solos sob floresta propiciaram menor resistência a penetração do que nos pastos.

Analisando-se o perfil do solo, a camada de maior resistência a penetração situou-se entre 0 e $15 \mathrm{~cm}$ de profundidade, ocorrendo queda gradual com o aumento de profundidade, tendência semelhante constatada por Leônidas (1998), Costa et al. (1999), Figueiredo et al. (2000) e Silva Filho et al. (2010). A partir dos $15 \mathrm{~cm}$ não se observou efeito da espécie de leguminosa forrageira e dos métodos de estabelecimento/preparo do solo na pressão aplicada. Demonstrando que as práticas de preparo do solo e de plantio foram capazes de romper o impedimento físico ao crescimento radicular das forrageiras em sua camada de 5 a $15 \mathrm{~cm}$ na qual, em média, a resistência a penetração foi de $18,2 \mathrm{kgf}^{-2}$, enquanto que nas parcelas controle os valores foram de 19,9 $\mathrm{kg} \mathrm{cm}^{-2}$, bastante próximos de $20,4 \mathrm{kgf} \mathrm{cm}^{-2}(2,0 \mathrm{MPa})$, considerado pela USDA (1993) como restritivo ao crescimento das raízes de várias culturas. No entanto, pela classificação proposta por Canarache (1990) todos os tratamentos mantiveram-se na faixa de baixa resistência a penetração (11,2 a $25,5 \mathrm{kgf} \mathrm{cm}^{-2}$ ou 1,1 a 2,5 MPa), apresentando pouca limitação ao crescimento do sistema radicular.

Isoladamente, a fertilização fosfatada não afetou $(P \geq 0,05)$ a resistência do solo à penetração, a não ser quando houve interação com as espécies de leguminosas forrageiras e com os métodos de estabelecimento/preparo do solo, no entanto, as respostas obtidas estiveram mais associadas aos dois últimos fatores, do que a fertilização em si. Na mesma área experimental, Costa et al.(2008) ao avaliarem a produção de forragem e composição botânica da pastagem, constataram que o plantio manual (matraca) e o roço dos pastos, associados à aplicação de fósforo foram os métodos mais eficientes para introdução do $D$. ovalifolium, com acúmulos de forragem de 9,6 e 10,1 t de $\mathrm{MS} \mathrm{ha}^{-1}$, e a leguminosa participando em 28 e 35\%, respectivamente para 
TOWNSEND, C.R. et al. Compactação de um Latossolo Amarelo sob pastagem submetida a diferentes métodos de introdução de leguminosas forrageiras. PUBVET, Londrina, V. 6, N. 13, Ed. 200, Art. 1339, 2012.

ambos os métodos. Com relação à introdução da $P$. phaseoloides, os acúmulos mais expressivos foram de 11,3 e 11,2 t de $\mathrm{MS} \mathrm{ha}^{-1}$, com participação de $18 \mathrm{e}$ $36 \%$ obtidos com os métodos em que o solo foi submetido à aração e aração + gradagem.

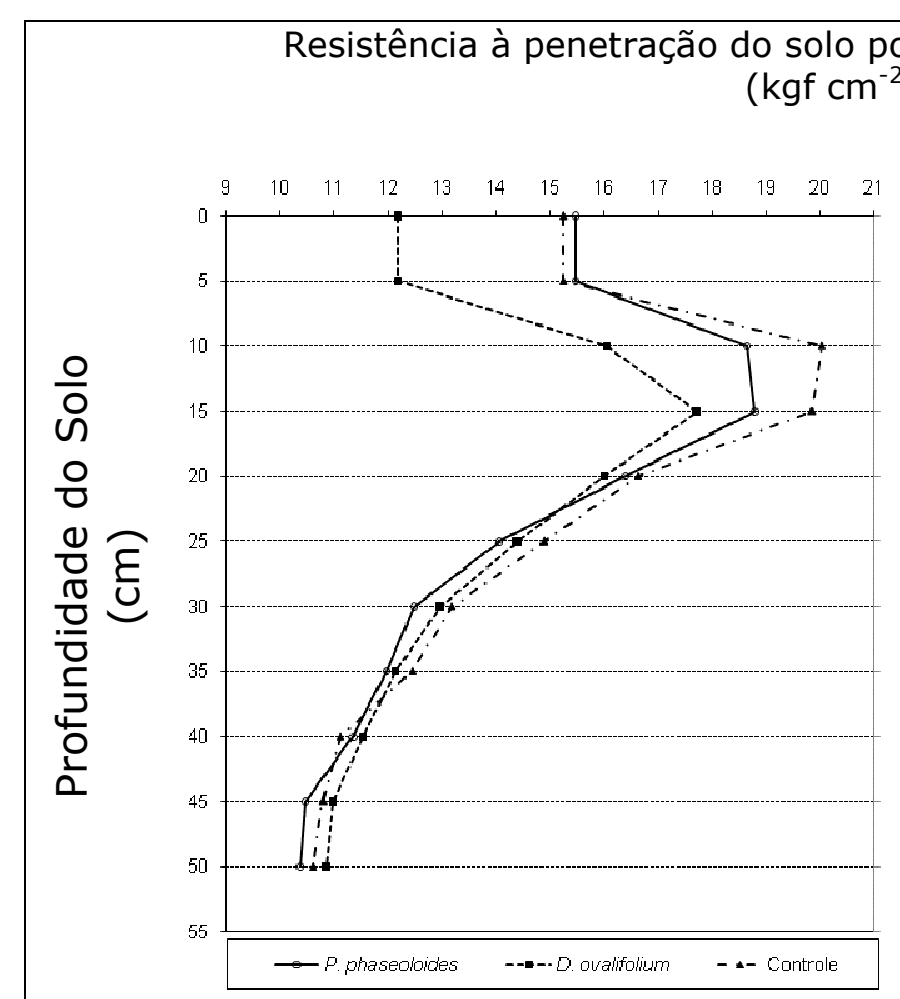

(a)

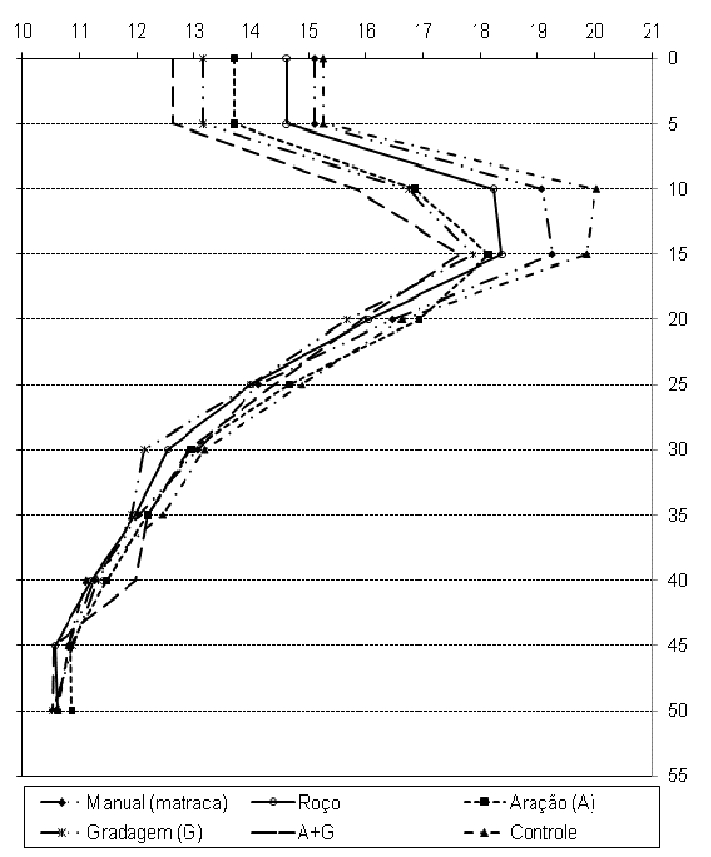

(b)

Figura 1. Efeito da introdução de leguminosas forrageiras (a) sob diferentes métodos de plantio e preparo de solo (b) na resistência a penetração em Latossolo Amarelo distrófico, textura argilosa, sob pastagens de Brachiaria brizantha cv. Marandu. Porto Velho-RO.

Nas pastagens onde o $D$. ovalifolium foi introduzido, independentemente do método de estabelecimento/preparo e fertilização fosfatada, o solo reteve maior umidade $(P>0,05)$, em relação àquelas em que $P$. phaseoloides foi estabelecida (Tabela 2), não havendo diferença de umidade no perfil do solo. Os resultados evidenciam o efeito da umidade do solo sobre a sua resistência a penetração, enfatizado por Klein et al. (1998). Manieri (2005) avaliou o efeito combinado da umidade e da densidade do solo na resistência à penetração, 

diferentes métodos de introdução de leguminosas forrageiras. PUBVET, Londrina, V. 6, N. 13, Ed. 200, Art. 1339, 2012.

utilizando um equipamento de medida simultânea da resistência e da umidade do solo (penetrômetro de impacto modelo Stolf combinado com sonda de TDR). O instrumento foi eficaz para mensurar simultaneamente, a resistência e a umidade ao longo do perfil do solo e que há grande variabilidade para esses atributos físicos do solo.

Tabela 2. Efeito da introdução de leguminosas forrageiras sob diferentes métodos de semeadura e preparo de solo nos teores de umidade em um Latossolo Amarelo distrófico, textura argilosa, sob pastagens de Brachiaria brizantha cv. Marandu. Porto Velho-RO.

\begin{tabular}{lccc}
\hline \multirow{2}{*}{\multicolumn{1}{c}{ Tratamentos }} & \multicolumn{2}{c}{ Profundidade do solo $(\mathrm{cm})$} & \multirow{2}{*}{ Média } \\
\cline { 2 - 3 } & $00-15$ & $15-30$ \\
\cline { 2 - 3 } & \multicolumn{3}{c}{ umidade (\%) } \\
\hline Leguminosa & 23,6 & 23,9 & 23,7 B \\
P. phaseoloides & 24,7 & 24,4 & $24,6 \mathrm{~A}$ \\
D. ovalifolium & 24,4 & 24,5 & 24,4 \\
\hline Método & 23,8 & 24,0 & 23,9 \\
Manual (matraca) & 24,5 & 23,1 & 23,8 \\
Roço & 24,3 & 24,6 & 24,4 \\
Aração (A) & 23,8 & 24,6 & 24,2 \\
Gradagem (G) & 24,2 & 24,1 & 24,2 \\
A+G & 23,5 & 23,7 & 23,6 \\
\hline Média & Controle & \multicolumn{3}{c}{ (G) } & \\
\hline \hline
\end{tabular}

Médias seguidas de letras diferentes, maiúsculas nas colunas e minúsculas nas linhas, diferem entre si (Tukey a $1 \%$ ).

\section{Conclusões}

A implantação de leguminosas forrageiras, com destaque ao $D$. ovalifolium e o método com maior revolvimento do solo (gradagem + aração) proporciona efeitos benéficos na redução da compactação do solo, notadamente na camada superficial $(0$ a $15 \mathrm{~cm})$.

\section{Referências Bibliográficas}

AZEVEDO, R.L.; RIBEIRO, G.T; AZEVEDO, C.L.L. Feijão guandu: uma planta multiuso. Revista da Fapese, v.3, n.2, p.81-86, 2007.

CAMARGO, O.A.; ALLEONI, L.R.F. Compactação do solo e desenvolvimento das plantas. Piracicaba: Esalq, 1997. 132p. 
CANARACHE, A. Penetrometric, a generalized semi-empirical model estimating soil resistance to penetration. Soil and Tillage Research, v.16, p.51-70, 1990.

COSTA, N. de L.; THUNG, M.; TOWNSEND, C.R. et al. Quantificação de características físicoquímicas do solo sob pastagens degradadas. Pasturas Tropicales, v.21, n.2, p74-77, 1999.

COSTA, N. de L.; TOWNSEND, C.R.; MAGALHÃES, J.A. et al. Recuperação de pastagens na Amazônia com leguminosas forrageiras. Pubvet, v.2, n.1, art.\#187, 17p., 2008.

DIAS FILHO, M.B. Degradação de pastagens: processos, causas e estratégias de recuperação. Belém: Embrapa Amazônia Oriental, 2.Ed., 2005, 173p.

EMBRAPA. Manual de análises químicas de solos, plantas e fertilizantes. Embrapa Solos. SILVA, F.C. da (Org.). Brasília: Embrapa Comunicação para Transferência de Tecnologia, 1999, 270p.

FIGUEIREDO, F.A. de; MENDES, A.M.; TOWNSEND, C.R. A influência do preparo do solo nas características físicas. In: REUNIÃO BRASILEIRA DE MANEJO E CONSERVAÇÃO DO SOLO E DE ÁGUA, 13., Ilhéus, Bahia, 2000. Anais... Ilhéus: SBCS/CEPLAC, 2000. (CD-ROM)

IDARON. Agência de Defesa Sanitária Agrossilvopastoril do Estado de Rondônia. Informe semestral de campo: referente à 290 etapa de vacinação. Porto Velho, maio, 2010, não paginado.

INPE. Instituto Nacional de Pesquisas Espaciais. Projeto PRODES. Monitoramento da floresta Amazônica brasileira por satélite. Estimativas anuais da taxa de desmatamento de 1988 a 2009. São José dos Campos, SP: INPE, 2009. Disponível em: <http://www.obt.inpe.br/prodes/prodes 1988 2009. htm>. Acesso em: 25 maio 2011.

KLEIN, V.A.; LIBARDI, P.L.; SILVA, A.P. Resistência do solo à penetração sob diferentes condições de densidade e teor de água. In: CONGRESSO BRASILEIRO DE ENGENHARIA AGRÍCOLA, 24., 1996, Jaboticabal. Anais... Jaboticabal: UNESP, 1998. p.45-54.

LEÔNIDAS, F. das C. Alterações físicas e químicas do solo sob pastagem na Amazônia Ocidental, submetido a diferentes períodos de utilização. Areia: UFPB, 1998. 56p. (Dissertação de Mestrado em Manejo de Solo e Água).

MANIERI, J.M. Utilização de um penetrômetro de impacto combinado com sonda de TDR para medidas simultâneas de resistência e de umidade do solo na avaliação da compactação em cana-de-açúcar. Campinas: IAC, 2005, 82p. (Dissertação de Mestrado em Agricultura Tropical e Subtropical).

NUMATA, I.; SOARES, J.V.; ROBERTS, D.A. et al. Relationships among soil fertility dynamics and remotely sensed measures across pasture chronosequences in Rondônia, Brazil. Remote Sensing of Environment, v. 87, p. 446-455, 2003.

REBELLO, F.K.; HOMMA, A.K.O. Uso da terra na Amazônia: uma proposta para reduzir desmatamentos e queimadas. Amazônia: Ciência e Desenvolvimento. v.1, n.1, p.197-234, 2005.

SERRÃO, E.A.S.; TOLEDO, J.M. Sustaining pasture-based production systems for the humid tropics. In: Development or destruction - the conversion of tropical forest to pasture in Latin America. DOWINIWG, T.E.; HECHT, S.B.; PEARSON, H.A.; GARCIA-DOWNING, C. (Eds.). Westuiew Press, Boulder, San Francisco, Oxford. 1994. p.257-280. 
SILVA FILHO, E.P da; COTTAS, L.R.; MARINI, G.B.S. Avaliação da compactação dos solos em áreas de pastagens e florestas em Porto Velho-Rondônia Boletim de Geografia, v.28, n.1, p.145-155, 2010.

STOLF, R. Teoria e tese experimental de fórmulas de transformação dos dados de penetrômetro de impacto em resistência do solo. Revista Brasileira de Ciência do Solo, v.15, p.229-235, 1991.

STOLF, R.; FERNANDES, J.; FURLANI-NETO, V.L. Recomendação para uso do penetrômetro de impacto modelo IAA/Planalsucar-Stolf. STAB. Açúcar, Álcool e Subprodutos, v.1, n.3, p.1823, 1983.

TOWNSEND, C.R.; COSTA, N. de L.; MENDES, A.M. et al. Nutrientes limitantes em solo de pastagens degradadas de Brachiaria brizantha cV. Marandu em Porto Velho-RO. In: REUNIÃO ANUAL DA SOCIEDADE BRASILEIRA DE ZOOTECNIA, 38. Piracicaba. Anais... Piracicaba: SBZ, 3p. 2001. (CD-ROM)

USDA, Soil survey manual. Washington, DC, USA, Soil Survey Division Staff, 1993. 437p. (Handbook, 18). 